\title{
Price relations between Malaysia rice sector and selected ASEAN countries
}

\begin{abstract}
Aim/Purpose: This research paper attempts to assess how the Malaysia rice industry will behave if and when certain changes occur, such as the removal of policies which affect its rice import price (namely the Vietnam rice floor export price and Thailand rice pledging scheme) and which result from the ongoing region economic integration embodied in ASEAN Vision 2020. Background: Malaysia rice farming sector compared to its ASEAN neighbors has a lower comparative advantage, this is transpiring in the lowering of the rice selfsufficiency targets and levels, moreover it is characterized as less efficiently managed compared to industrial farms. Therefore, Malaysia will continue to be a net importer of rice. It is against the background that this research was done, to anticipate how the Malaysia rice industry would behave if and when the existing trade barriers in the ASEAN rice market are removed and for the adjustment of Malaysia rice farming parameters to meet the desired state of rice selfsufficiency level. Methodology: A system dynamics model of Malaysia rice sector with consideration of its rice import prices from ASEAN trade partners was built and tested to check if it mimics real world behavior pattern. Nevertheless, the exercise in which the model built was purposed is to foresight, the ability to anticipate how the system will behave if and when certain changes occur and a tool for policy design, it is not forecasting and it does not depend on the ability to predict. Contribution: This study is in the line with previous related studies with the concern of the impact of trade liberalization on the global as well as ASEAN rice market. However, the beauty of the methodology applied is into taking account of nonlinear relationship among variables of the system, the feedback loop mechanism, time delays, and the incorporation of all variables that are relevant to the problem endogenously. Thus, the model simulation results are driven not by external factors, but by the internal structure of the model. The internal structure made of the feedback loos formed by the interdependency between variables. Findings: Simulation results obtained from different Malaysia rice import price scenarios indicate a downtrend of the Malaysia rice self-sufficiency level and of less importance; the change is less than one percentage point. Recommendations for Practitioners: Given the long run trend relationship between the rice import prices and the self-sufficiency levels, it may be advisable to policy makers to let the economic arguments for open trade with the risk of an increasing trend of import prices. It also prevails over the food security arguments, which might be involved in unintended consequences resulting from different forms of government intervention in the market. Recommendation for Researchers: There is a need to continue to conduct test based on new scenarios and model assumptions. New research to assess the impact of selected ASEAN countries price policies on Malaysia rice industry may produce different results and recommendations. For example if we assume these selected ASEAN countries price policies are moving towards a free trade orientation, as well as the Malaysia rice industry. Impact on Society: Food security is essential to the survival of the society. Thus, the supply of a staple commodity such as rice in Malaysia is essential to the social, political and economic stability of the society. Understanding the supply and demand conditions affecting the distribution of this product in the Country is critical for public and private policy making about the development of the economy and society. Rice commodity was conceptualized as a normal good in this study and we gained an insight on the rice consumption per capita behavior through different Malaysia rice import prices. What if the rice
\end{abstract}


commodity is conceptually modeled as an inferior good, definitely rice consumption per capita behavior will change, with its associated impact on the economy and society. This study enables us to investigate the possible outcomes for various scenarios. Future Research: For further research, this system dynamics model of Malaysia rice industry can be improved by including some variables closely related to trade such as the exchange rate between the United States dollar and ASEAN countries currency. In addition, some other variables (e.g. oil price) which can affect the rice production such as the climate change and some variables on the rice consumers side such as the changing consumer preferences (normal Vs inferior commodity), or on the rice/paddy farmers side such as poverty alleviation.

Keyword: Rice trade; Food security; Policy analysis; System dynamics; Malaysia; ASEAN 